\title{
Comparison of Clinical Importance of Drug Interactions Identified by Hospital Pharmacists and a Local Clinical Decision Support System
}

\author{
Louise Lau, Harkaryn Bagri, Michael Legal, and Karen Dahri
}

Can J Hosp Pharm. 2021;74(3):203-10

DOI: 10.4212/cjhp.v74i3.3147

\begin{abstract}
Background: Drug-drug interactions (DDIs) may cause adverse drug events, potentially leading to hospital admission. Clinical decision support systems (CDSSs) can improve decision-making by clinicians as well as drug safety. However, previous research has suggested that pharmacists are concerned about discrepancies between CDSSs and common clinical practice in terms of severity ratings and recommended actions for DDIs.
\end{abstract}

Objectives: The primary objective was to characterize the level of agreement in terms of DDI severity ranking and actions recommended between the local CDSS and pharmacists. The secondary objectives were to determine the level of agreement among pharmacists concerning DDI severity, to determine the influence of the CDSS on clinicians' decision-making, and to review the literature supporting the severity rankings of DDIs identified in the study institution's database.

Methods: This 2-part survey study involved pharmacists and pharmacy residents working at 1 of 4 health organizations within the Lower Mainland Pharmacy Services, British Columbia, who were invited to participate by email. Participants were first asked to rank the severity of 15 drug pairs (representing potential DDIs) on a 5-point Likert scale and to select an action to manage each interaction. Participants were then given the CDSS severity classification for the same 15 pairs and again asked to select an appropriate management action.

Results: Of the estimated 500 eligible pharmacists, a total of 73 pharmacists participated, for a response rate of about $15 \%$. For DDIs of moderate severity, most participants chose to monitor. For severe and contraindicated interactions, the severity ranking and action proposed by participants varied, despite the same severity classification by the CDSS. There was poor agreement among respondents about the severity of the various DDIs. Moreover, knowledge of the CDSS severity ranking did not seem to change the actions proposed by most respondents.

Conclusion: This study identified a gap between the local CDSS and clinical practice. There were discrepancies in terms of severity rankings and actions proposed to manage DDIs, particularly for severe and contraindicated DDIs. The current CDSS did not appear to have a large impact on clinical decision-making, which suggests that it may not be functioning to its full potential.

Keywords: drug-drug interactions, clinical decision support system

\begin{abstract}
RÉSUMÉ
Contexte : Les interactions médicamenteuses (IM) peuvent provoquer des réactions indésirables et entraîner potentiellement une admission à l'hôpital. Les systèmes d'aide à la décision clinique (SADC) peuvent améliorer le processus de prise de décision des cliniciens ainsi que la sécurité de l'usage des médicaments. Cependant, des recherches antérieures mentionnent que les divergences entre les SADC et la pratique clinique courante de l'évaluation de la gravité des IM ainsi que les mesures recommandées préoccupent les pharmaciens.
\end{abstract}

Objectifs : L'objectif principal consistait à caractériser le degré de concordance entre les SADC locaux et les décisions des pharmaciens en termes d'évaluation du degré de gravité des IM ainsi que des mesures recommandées. Les objectifs secondaires visaient quant à eux à déterminer le degré de concordance entre l'évaluation du degré de gravité de I'IM par les pharmaciens, à définir l'influence des $S A D C$ sur le processus de prise de décision des cliniciens et à examiner la documentation appuyant les critères d'évaluation de la gravité d'une IM, déterminés dans la base de données de l'institution où s'est déroulée l'étude.

Méthodes : Cette étude en deux volets, menée au moyen d'un sondage par courriel, impliquait les pharmaciens et les résidents en pharmacie travaillant dans I'un des quatre organismes de santé des Lower Mainland Pharmacy Services en Colombie-Britannique. On a tout d'abord demandé aux participants d'évaluer le degré de gravité de 15 paires de médicaments (représentant des IM potentielles) sur une échelle de Likert à 5 points et de choisir une mesure visant à gérer chaque interaction. Les participants ont ensuite reçu l'évaluation par les SADC de la gravité des mêmes 15 paires; on leur a ensuite demandé de choisir une mesure de gestion appropriée.

Résultats : Sur une estimation de 500 pharmaciens admissibles, 73 ont participé à l'étude et le taux de réponse s'est établi à $15 \%$. Concernant les IM dont le degré de gravité est modéré, la plupart des participants ont choisi la surveillance. L'évaluation du degré de gravité et les mesures proposées par les participants variaient lorsqu'il s'agissait d'interactions contre-indiquées et graves, et cela malgré une évaluation identique du degré de gravité par les SADC. On a relevé une mauvaise concordance entre les répondants quant à la gravité des diverses IM. De plus, la prise de connaissance par les répondants de l'évaluation du degré de gravité faite par les SADC ne semblait pas modifier les mesures proposées par la plupart d'entre eux.

Conclusion : Cette étude a mis en évidence un fossé entre les SADC locaux et la pratique clinique. On y a relevé des divergences entre l'évaluation du degré de gravité des IM et les mesures proposées pour les gérer, en particulier lorsque les IM sont graves et contre-indiquées. Le SADC utilisé couramment ne semble pas avoir d'impact important sur le processus de décision clinique, ce qui laisse supposer qu'il pourrait ne pas fonctionner au maximum de son potentiel.

Mots-clés : interactions médicamenteuses, système d'aide à la décision clinique 


\section{INTRODUCTION}

Adverse drug events that arise from drug-drug interactions (DDIs) account for $2 \%$ to $3 \%$ of hospital admissions, despite most DDIs being predictable. ${ }^{1}$ Since there are thousands of DDIs in existence, clinicians often depend on clinical decision support systems (CDSSs) to alert them to potential DDIs. ${ }^{2}$ Many different types of CDSS have been designed to alert clinicians to potential DDIs, classify their severity, and suggest appropriate courses of action to reduce the risk of patient harm. A well-designed CDSS can improve decisionmaking and enhance patient care by making such care safer, more effective, and more efficient. ${ }^{3}$ Unfortunately, CDSS use has also given rise to a phenomenon known as "alert fatigue", which results from repetitive exposure to irrelevant alerts. ${ }^{4,5}$ Excessive numbers of inappropriate or clinically insignificant interactions are often flagged. Other complaints about CDSSs include lack of patient specificity, lack of clinical relevance, and lack of "actionable" recommendations. ${ }^{6}$ Avoiding alert fatigue depends on obtaining pertinent, beneficial information without the burden of irrelevant alerts.

To further complicate matters, there is a lack of standardization of CDSSs because each vendor individualizes its approach to evaluating and classifying DDIs. ${ }^{7}$ Therefore, the ability of different CDSSs to alert users to clinically important DDIs varies widely. ${ }^{8-10}$ The major challenges of creating a suitable CDSS is knowing what information to transmit and how to display it. ${ }^{3}$ Some studies have attempted to modify the program interface to make it more user-friendly (e.g., by simplifying screen displays and reducing the number of pop-ups). ${ }^{11,12}$ Others have investigated the key pieces of information and functions that an ideal CDSS should incorporate. ${ }^{13}$ In previous work conducted by our research group, pharmacists made various recommendations to increase the utility of the local system, such as colour coding alerts and eliminating duplicate alerts. ${ }^{6} \mathrm{~A}$ common concern among these pharmacists was the substantial discrepancy in level of severity and recommended actions between the local CDSS and what they would do in practice.

To our knowledge, no studies to date have examined the level of agreement between pharmacists and a CDSS for specific drug interactions. Consistency between the CDSS and pharmacists using the system would suggest that the CDSS output is relevant and effective, whereas inconsistencies would indicate that the local CDSS can be further improved. Therefore, the primary objective of this research was to compare the level of agreement in DDI severity rankings and actions recommended between the local CDSS and clinical pharmacists. The secondary objectives were to determine the level of agreement among pharmacists about the severity of various DDIs, to determine the influence of the CDSS on clinical decision-making, and to review the evidence supporting the severity classification of DDIs identified in our database. The ultimate aim of this study was to help identify some of the gaps in creating an ideal CDSS by exploring the utility of the local CDSS with respect to its impact on clinical decision-making and its agreement with pharmacists' knowledge and experience and the current literature.

\section{METHODS}

\section{Study Design}

This study used survey methodology to examine the level of agreement between pharmacists' clinical decision-making and CDSS recommendations for a prespecified set of drugdrug combinations. The 2-part survey also explored the effect of the CDSS severity ranking and recommendations on pharmacists' decision-making. In addition, a literature review was completed to determine the severity level of the DDIs as listed in other databases and the evidence supporting the DDI severity classification, to assist in verifying the accuracy of the CDSS classification (where the latter is based on DDI information from a database managed by First Databank, August 2018 version).

The Behavioural Research Ethics Board at the University of British Columbia approved the study before recruitment began, and informed consent was obtained from all participants. The overall study period, including survey development and analysis, was November 2018 to June 2019.

\section{Study Population}

Pharmacists and pharmacy residents working across 4 health organizations (Fraser Health, Vancouver Coastal Health, Providence Health, and Provincial Health Services Authority) within Lower Mainland Pharmacy Services, in British Columbia, were invited to participate. Pharmacy personnel in the following roles were eligible to participate: dispensary pharmacists, nondispensary pharmacists, and pharmacy residents employed within the health authority. Dispensary pharmacists spend $100 \%$ of their shifts in the dispensary and do not work on any hospital ward. Nondispensary pharmacists and pharmacy residents spend at least some portion of their shifts working on a hospital ward. Pharmacists not employed by 1 of the 4 health organizations and pharmacy technicians were excluded from the survey.

\section{Sampling Method}

The invitation to complete the survey was sent to potential participants by pharmacy administrative assistants using group email lists. The survey was open for a total of 9 weeks (January 29 to April 6, 2019) and was housed within Qualtrics (Qualtrics Inc, version May 2019), a survey tool provided by the University of British Columbia.

The university's privacy impact assessment process has been applied to the survey tool, to assess the privacy and 
security of the university's systems in relation to the tool. Information collected using the survey tool was kept secure by various measures, including data encryption. Participants had the opportunity to enter a draw for one of a pair of $\$ 20$ gift cards by providing their email address at the end of the survey. To preserve the anonymity of responses, email addresses were unlinked from survey responses during the data analysis and kept in a separate document. Two weeks after the initial invitation, a reminder email was sent to potential participants.

\section{Survey Development}

The survey questions were based on a uniquely selected set of 15 DDIs (Figure 1). To generate the list of DDIs, the pharmacy information technology department at Vancouver General Hospital generated a list of DDIs flagged during clinical care in 2016, along with the frequency with which they were flagged and the severity classification category applied by the CDSS. From that list, the 20 most frequently flagged DDIs and those flagged only once were chosen. Duplicate DDIs that involved similar pharmacological mechanisms and had the same severity (e.g., CYP3A4 inhibition of moderate severity) as well as those with similar consequences and the same severity (e.g., QTc prolongation of moderate severity) were excluded. Each remaining DDI was assigned a number, and a final set of the 10 most frequently identified and 5 least frequently identified unique DDIs were selected by means of a random number generator. A larger number of DDIs from the most flagged category was chosen to reflect the DDIs most often encountered and likely contributing to alert fatigue, whereas a small sample of the least flagged DDIs was included with the aim of avoiding any potential bias because of participants already knowing the severity of DDIs that are commonly seen in practice. Among the 15 DDIs selected, 8 were of moderate severity, 5 were severe, and 2 were contraindicated, according to the CDSS severity ranking. The DDI selection process was presented to 10 relevant stakeholders (pharmacy residents and pharmacists with different years of experience, selected through convenience sampling) for further refinement. In addition, another group of 4 pharmacists, also selected through convenience sampling, reviewed the chosen DDIs and trialled the survey before it was finalized.

The survey consisted of 2 parts (survey questions available from the corresponding author by request). First, the participants were asked to rank the severity of each prespecified DDI on a Likert-type scale of 1 to 5, where 1 represented interactions of no consequence and 5 represented combinations that were contraindicated. Nondispensary pharmacists and pharmacy residents responding to the survey were asked to select 1 of 3 actions to manage the interaction, according to what they would do in practice: take no action; order appropriate laboratory tests to monitor for drug interaction and/or assess the patient for suitable monitoring; or contact the prescriber to discuss the interaction and/or propose an alternative recommendation. Dispensary pharmacists responding to the survey were given a related but somewhat different set of options because of differences in their scope of practice. These pharmacists had the following 3 options: take no action, flag the interaction for the clinical pharmacist to follow up the next day, or immediately contact the clinical pharmacist or the prescriber to discuss the interaction or make an alternative recommendation.

The second part of the survey was administered immediately after the first. Participants were presented with the same 15 DDIs, along with the severity level of each DDI as ranked by the CDSS and the action recommended by the CDSS. The CDSS recommendations were as followed: for mild interactions, monitor and take no action; for moderate interactions, assess the risk to the patient and take action as needed; for severe interactions, take action as required to reduce the risk of severe adverse interactions; and for interactions that were contraindicated, avoid administering the drug combination. The participants were then asked

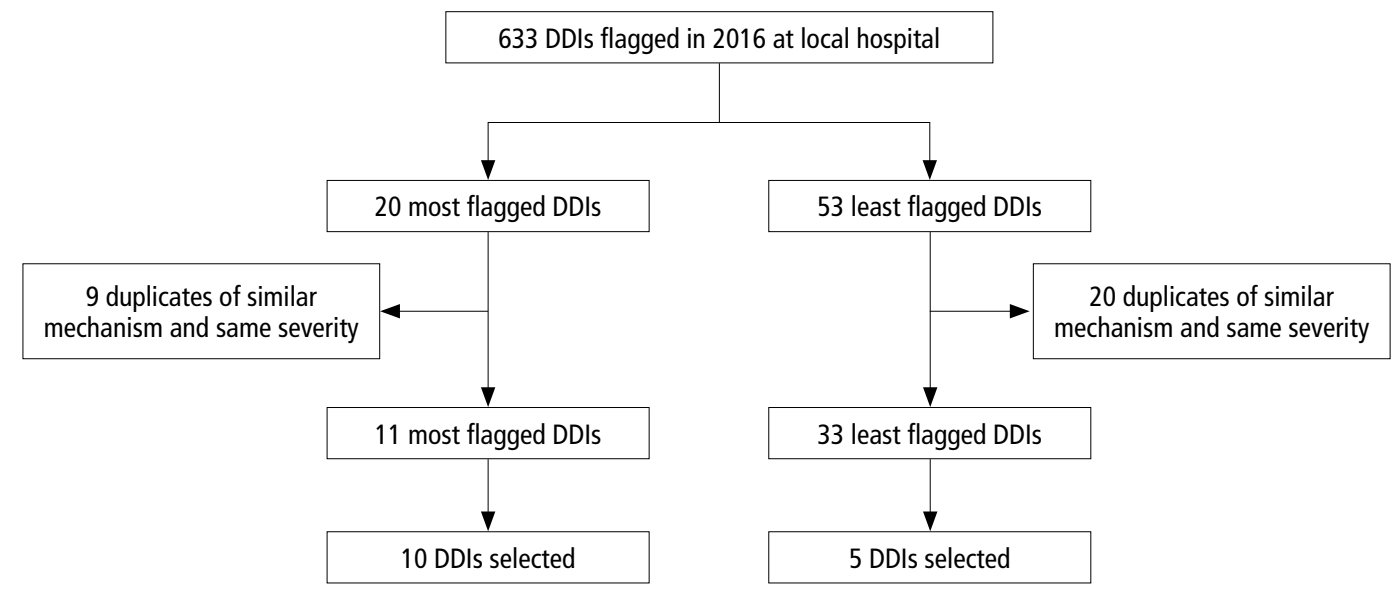

FIGURE 1. Selection of drug-drug interactions (DDIs) for the survey. 
to again select how they would manage the interaction, without having access to their responses in the first part of the survey, to determine the impact of the CDSS on pharmacists' decision-making. In addition, they were asked to rate, on a scale of 0 (none) to 5 (extremely large), how seeing the severity ranking of the CDSS altered their approach. Finally, participants were asked to list, in an open-text field, other factors or assumptions they made while completing the survey.

\section{Literature Review}

A literature search was conducted for the prespecified DDIs to examine the evidence related to each DDI and the severity level assigned by the CDSS. First, a commercial database, Lexicomp ${ }^{\circledR}$ Drug Interactions (UpToDate, Inc, () 2019) was viewed to determine the severity of the interaction. A literature search was then conducted within MEDLINE Ovid (1946 to November 2019) and Embase Ovid (1974 to November 2019) using search terms that included the specific drug pair involved (e.g., "quetiapine" and "citalopram") and the term "interaction" or "adverse effects". The references used in the commercial database were also reviewed for additional information. The literature search was completed by one of the co-investigators (L.L.) and verified by another researcher on the team (K.D.).

\section{Statistical Analysis}

Descriptive statistics were used to report baseline characteristics and to assess the primary and secondary outcomes of the study. A Fleiss kappa value was calculated to determine the inter-rater agreement among participants on the overall severity ranking and actions proposed for each DDI. The respective totals for each severity category and each action category for each DDI were summed manually and entered into a Fleiss kappa calculator (http://justusrandolph .net/kappa/). The actions proposed by the dispensary pharmacists were excluded from calculation of the Fleiss kappa, because the options presented to them were different from the options presented to nondispensary pharmacists and pharmacy residents.

\section{RESULTS}

\section{Demographic Characteristics}

An estimated 500 pharmacists and pharmacy residents were invited to participate, and 73 fully completed responses were collected (response rate about 15\%), 51 (70\%) from ward/dispensary pharmacists, 4 (5\%) from dispensary-only pharmacists, and 18 (25\%) from pharmacy residents.

\section{Part 1: Respondent Ranking and Proposed Actions}

DDIs ranked as "moderate" by the CDSS were most commonly ranked by participants as 2 or 3 out of 5 on the Likerttype scale (Table 1 ). There was greater variability in ranking for both the severe and the contraindicated DDIs. Two of the severe DDIs (clozapine-rifampin and mebendazolemetronidazole) were ranked as 4 or 5 , whereas the other severe DDIs (citalopram-quetiapine, clozapine-lorazepam, fluoxetine-metoclopramide) were commonly ranked as 2 or 3, despite their classification as "severe" by the CDSS. A similar discrepancy was found for the 2 contraindicated DDIs: the carbamazepine-voriconazole combination was considered more severe than clopidogrel-pioglitazone by many of the participants. Overall, the inter-rater agreement for severity ranking of all DDIs, among nondispensary pharmacists and pharmacy residents, was 35\%.

In terms of proposed actions, most participants selected "monitor" to manage 11 of the DDIs, which were most frequently ranked as either 2 or 3 on the severity scale. Among the remaining DDIs, "contact prescriber" was the most frequently selected option for 3 of the DDIs (2 classified as severe and 1 contraindicated by the CDSS). These 3 DDIs were most commonly ranked as 4 or 5 on the severity scale by participants. There was only $1 \mathrm{DDI}$, involving paroxetine and pravastatin, for which the most frequently selected response was "no action". This DDI was ranked as having moderate severity by the CDSS and was most commonly ranked as 2 on the severity scale by participants. The overall inter-rater agreement in terms of actions proposed, among nondispensary pharmacists and pharmacy residents, was $57 \%$.

\section{Part 2: Pharmacists' Decision-Making Based on CDSS Information}

Table 2 shows the proportions of participants who did and did not change the action proposed for each DDI after learning the CDSS severity classification and recommendation. Most participants did not change their response with this additional information. More specifically, on average, only $15.8 \%$ of participants proposed a different action to manage the DDI in part 2 of the survey. Interestingly, when asked "on a scale of 0 (none) to 5 (extremely large), to what degree did seeing the severity ranking by the computer system [CDSS] alter your approach", the largest proportion of participants selected $2(30.1 \%)$ and $3(26.0 \%)$, with only 4 participants selecting 0 (5.5\%). As such, it appears that participants felt the CDSS had some degree of influence on their actions, although this was not entirely reflected in the comparison of responses shown in Table 2.

\section{Literature Review}

For each DDI included in this study, the level of severity identified by the tertiary reference (Lexicomp Drug Interactions database) was either moderate or major (Table 3). Even when differences in terminology were taken into account, there was a lack of agreement in severity classification between the CDSS and the tertiary reference (Table 3). For example, for the 8 DDIs categorized as moderate by the 


\begin{tabular}{|c|c|c|c|c|c|c|c|c|}
\hline \multirow[b]{2}{*}{ Combination $^{\mathrm{a}}$} & \multicolumn{5}{|c|}{$\begin{array}{l}\text { Respondent's Severity Ranking } \\
\quad \% \text { of Respondents } \\
(n=73)\end{array}$} & \multicolumn{3}{|c|}{$\begin{array}{l}\text { Respondent's Proposed Action; } \\
\% \text { of Respondents' }(n=73)\end{array}$} \\
\hline & 1 & 2 & 3 & 4 & 5 & No Action & Monitor & Contact \\
\hline \multicolumn{9}{|l|}{ Moderate } \\
\hline ASA and prednisone & 20.5 & 43.8 & 30.2 & 5.5 & 0.0 & 40.6 & 55.1 & 4.3 \\
\hline Citalopram and trazodone & 12.3 & 42.5 & 36.9 & 8.3 & 0.0 & 31.9 & 63.8 & 4.3 \\
\hline Clopidogrel and warfarin & 6.8 & 17.8 & 38.4 & 35.6 & 1.4 & 11.6 & 73.9 & 14.5 \\
\hline Furosemide and ramipril & 32.9 & 39.7 & 26.0 & 1.4 & 0.0 & 24.6 & 75.4 & 0.0 \\
\hline Glyburide and propranolol & 19.2 & 49.3 & 26.0 & 4.1 & 1.4 & 30.4 & 60.9 & 8.7 \\
\hline Hydromorphone and prochlorperazine & 21.9 & 41.1 & 32.9 & 4.1 & 0.0 & 42.0 & 55.1 & 2.9 \\
\hline Paroxetine and pravastatin & 27.4 & 50.7 & 20.5 & 1.4 & 0.0 & 47.8 & 43.5 & 8.7 \\
\hline Ramipril and potassium chloride (PO) & 4.1 & 47.9 & 42.5 & 5.5 & 0.0 & 7.2 & 91.3 & 1.4 \\
\hline \multicolumn{9}{|l|}{ Severe } \\
\hline Citalopram and quetiapine & 6.8 & 43.8 & 43.8 & 4.1 & 1.4 & 23.2 & 73.9 & 2.9 \\
\hline Clozapine and lorazepam & 15.1 & 23.3 & 35.6 & 24.7 & 1.4 & 26.1 & 55.1 & 18.8 \\
\hline Clozapine and rifampin & 1.4 & 1.4 & 12.3 & 45.2 & 39.7 & 1.4 & 26.1 & 72.5 \\
\hline Fluoxetine and metoclopramide & 9.6 & 28.8 & 45.2 & 15.1 & 1.4 & 21.7 & 59.4 & 18.8 \\
\hline Mebendazole and metronidazole & 5.5 & 2.7 & 8.2 & 19.2 & 64.4 & 7.2 & 8.7 & 84.1 \\
\hline \multicolumn{9}{|l|}{ Contraindicated } \\
\hline Carbamazepine and voriconazole & 0.0 & 1.4 & 6.8 & 31.5 & 60.3 & 0.0 & 17.4 & 82.6 \\
\hline Clopidogrel and pioglitazone (>15 mg) & 17.8 & 34.2 & 31.5 & 12.3 & 4.1 & 27.5 & 56.5 & 15.9 \\
\hline
\end{tabular}

ASA = acetylsalicylic acid.

a Categorized according to severity of interactions, as per the local clinical decision support system.

bLikert-type scale, ranging from 1 (no consequence) to 5 (combination contraindicated).

'For each drug combination, the most common response is highlighted in bold.

CDSS, the tertiary reference categorized 5 as "moderate" and 3 as "major". Similar discrepancies occurred for the DDIs categorized by the CDSS as severe and contraindicated, further highlighting the lack of consistency among various databases.

In terms of the primary evidence discovered in the literature search, the best evidence for most of the DDIs was often of low quality (i.e., cohort studies and case reports). Furthermore, not all of the studies identified were specific to the drug pair involved; instead, many were based on drugs from the same class.

\section{DISCUSSION}

A previous study by our research group showed that pharmacists believed there was a discrepancy between the local CDSS and what they would do in practice in terms of DDI severity classification; they also believed that the current system was performing suboptimally in the identification of clinically important DDIs. ${ }^{6}$ An effective CDSS should provide clinicians with useful information and recommendations that are applicable to practice. As such, a CDSS that is performing optimally could be expected to make recommendations that are aligned with how pharmacists manage DDIs in practice. The results of the current survey study highlight inconsistencies in severity rankings of DDIs between the CDSS and practising pharmacists and also differences in the evaluation of DDIs among different pharmacists. Such results may stem from the lack of strong evidence supporting the severity rankings and management of DDIs, as was found in our literature search. Overall, there is a limited body of evidence to guide the best course of action in specific clinical situations.

DDIs are prevalent even in highly monitored settings, such as hospitals. One meta-analysis showed that $33 \%$ of general medicine patients and $67 \%$ of intensive care patients experienced a potential DDI while in hospital. ${ }^{14}$ The larger the number of drugs that a patient is receiving, the greater the likelihood of potential DDIs. Adverse drug reactions are the most concerning outcomes of DDIs, and such reactions are well documented in literature. In a single-hospital retrospective study, $63 \%$ of the study population had experienced at least $1 \mathrm{DDI} .{ }^{15}$ More importantly, the authors found that the presence of 3 or more interactions and the duration of exposure to the interaction were independently associated with mortality. Given the prevalence of DDIs seen in the hospital setting and their potential consequences, there is a need for better evidence and a clearer decision framework within the CDSS to help guide clinicians in optimizing patient care.

One notable result from this survey was that the severity rankings by participants were higher on the Likert scale, at 
TABLE 2. Comparison of Action Proposed ${ }^{a}$ to Manage DDIs before and after Learning the Relevant CDSS Severity Ranking and Recommendation

\begin{tabular}{|c|c|c|}
\hline \multirow[b]{2}{*}{ Combination ${ }^{b}$} & \multicolumn{2}{|c|}{$\begin{array}{l}\text { Influence of CDSS on Response; } \\
\quad \% \text { of Respondents }(n=73)\end{array}$} \\
\hline & $\begin{array}{l}\text { Changed } \\
\text { Response }\end{array}$ & $\begin{array}{l}\text { Did Not Change } \\
\text { Response }\end{array}$ \\
\hline \multicolumn{3}{|l|}{ Moderate } \\
\hline ASA and prednisone & 15.9 & 84.1 \\
\hline Citalopram and trazodone & 15.9 & 84.1 \\
\hline Clopidogrel and warfarin & 13.0 & 87.0 \\
\hline Furosemide and ramipril & 13.0 & 87.0 \\
\hline Glyburide and propranolol & 15.9 & 84.1 \\
\hline $\begin{array}{l}\text { Hydromorphone and } \\
\text { prochlorperazine }\end{array}$ & 15.9 & 84.1 \\
\hline Paroxetine and pravastatin & 29.0 & 71.0 \\
\hline $\begin{array}{l}\text { Ramipril and potassium } \\
\text { chloride (PO) }\end{array}$ & 13.0 & 87.0 \\
\hline \multicolumn{3}{|l|}{ Severe } \\
\hline Citalopram and quetiapine & 13.0 & 87.0 \\
\hline Clozapine and lorazepam & 17.4 & 82.6 \\
\hline Clozapine and rifampin & 11.6 & 88.4 \\
\hline $\begin{array}{l}\text { Fluoxetine and } \\
\text { metoclopramide }\end{array}$ & 23.2 & 76.8 \\
\hline $\begin{array}{l}\text { Mebendazole and } \\
\text { metronidazole }\end{array}$ & 5.8 & 94.2 \\
\hline \multicolumn{3}{|l|}{ Contraindicated } \\
\hline $\begin{array}{l}\text { Carbamazepine and } \\
\text { voriconazole }\end{array}$ & 10.1 & 89.9 \\
\hline $\begin{array}{l}\text { Clopidogrel and pioglitazone } \\
\text { (>15 mg) }\end{array}$ & 24.6 & 75.4 \\
\hline
\end{tabular}

ASA = acetylsalicylic acid, DDI = drug-drug interaction, $\mathrm{CDSS}=$ clinical decision support system.

The choices of management options for nondispensary pharmacists and pharmacy residents were no action, monitor, or contact prescriber; the choices of management options for dispensary pharmacists were no action, flag clinical pharmacist, or immediately contact clinical pharmacist or prescriber. The data presented in this table are based on whether, for a particular DDI, the respondent's proposed action to manage the DDI changed between part 1 and part 2 of the survey, where part 2 entailed the respondent having knowledge of the CDSS recommended action. ${ }^{b}$ Categorized according to severity of interactions, as per the local CDSS.

4 or 5 , for DDIs that involved antimicrobials: carbamazepinevoriconazole (contraindicated), clozapine-rifampin (severe), and mebendazole-metronidazole (severe). Moreover, for all 3 of these interactions, most of the participants stated that they would contact the prescriber rather than monitor or take no action. These results suggest that the acuity of the clinical situation often influences a pharmacist's decision in the management of DDI. Perhaps a useful approach in designing a CDSS would be to ensure that the system takes into consideration various patient-specific factors when making recommendations for its users, rather than simply classifying each DDI by severity. For example, for DDIs that might increase the risk of bleeding, factors such as the patient's age, history of bleeding, and hemoglobin level could be taken into consideration. An algorithm approach that incorporates patient-specific parameters can help to better stratify individualized risks and could potentially be more applicable in practice. Moreover, one of the most frequent actions proposed by participants in this study was to "monitor". A useful feature to increase the utility of a CDSS would be to outline specific monitoring parameters for each DDI.

This study had a few limitations related to the survey design. First, participants were asked to use a Likert-type scale of 1 (interaction of no consequence) to 5 (combination contraindicated) to rank the severity of each DDI, rather than terminology such as "mild", "moderate", "severe", or "contraindicated", as used by the CDSS. Our intention was to avoid potential bias, given that participants might have been familiar with the CDSS ranking before answering the survey, and this familiarity might have influenced their responses. The challenge of using a Likert-type scale in this survey was the inability to reconcile and quantify the level of agreement between the CDSS and participants. If the survey were to be conducted at other hospitals that use different CDSSs with different terminology and classifications, the results might be different. In addition, the Likert scale was not validated, which limits the reliability of the survey responses.

Another limitation to the survey design was administration of part 2 immediately after part 1 . The participants might have recalled their responses from the first part of the survey, which could have affected their responses in the second part, resulting in an underestimate of the impact of the CDSS on clinical decision-making. Furthermore, no clinical context was provided, so responses might have varied depending on the area of practice and expertise of the individual participants. The dose, duration, and frequency for each DDI were also not provided to participants, because the CDSS often does not take into consideration the dosing regimens. For almost all DDIs in the survey, the CDSS severity ranking would be the same, regardless of dose, duration, or frequency. One exception is the DDI involving clopidogrel and pioglitazone, which is categorized as contraindicated if the dose of pioglitazone is greater than $15 \mathrm{mg}$. In the open-text field at the end of the survey, a number of participants expressed that frequency, dose, and duration of therapy would greatly affect their approach to managing each DDI. For consistency, we did not provide dosing information for any of the DDIs. Therefore, the results may vary depending on assumptions about dosing regimens that participants made while completing the survey. Our rationale for this aspect of survey design was to allow our results to be generalizable and to reflect the reality of the CDSS, which does not take into consideration the clinical context, dosing regimen, or patient-specific factors. 
TABLE 3. Results of Literature Evidence Supporting Selected Drug-Drug Interactions

\begin{tabular}{|c|c|c|c|}
\hline Combination & Ranking as per CDSS & Ranking as per Tertiary Reference ${ }^{a}$ & Best Evidence $^{b}$ \\
\hline ASA and prednisone & Moderate & Moderate & $5 \mathrm{~A}$ \\
\hline Citalopram and trazodone & Moderate & Major & $5 B$ \\
\hline Clopidogrel and warfarin & Moderate & Major & $3 B$ \\
\hline Furosemide and ramipril & Moderate & Moderate & $3 B$ \\
\hline Glyburide and propranolol & Moderate & Moderate & $3 B$ \\
\hline Hydromorphone and prochlorperazine & Moderate & Major & $3 B$ \\
\hline Paroxetine and pravastatin & Moderate & Moderate & $3 \mathrm{~A}$ \\
\hline Ramipril and potassium chloride (PO) & Moderate & Moderate & $3 B$ \\
\hline Citalopram and quetiapine & Severe & Moderate & $3 B$ \\
\hline Clozapine and lorazepam & Severe & Major & $5 \mathrm{~A}$ \\
\hline Clozapine and rifampin & Severe & Major & $5 A$ \\
\hline Fluoxetine and metoclopramide & Severe & Moderate & $6 \mathrm{~A}$ \\
\hline Mebendazole and metronidazole & Severe & Major & $4 \mathrm{~A}$ \\
\hline Carbamazepine and voriconazole & Contraindicated & Major & $5 A$ \\
\hline Clopidogrel and pioglitazone (>15 mg) & Contraindicated & Moderate & $6 \mathrm{~A}$ \\
\hline
\end{tabular}

ASA $=$ acetylsalicylic acid, CDSS = clinical decision support system.

a Lexicomp ${ }^{\circledR}$ Drug Interactions database (2019).

bEvidence types (not all types occurred in this study): $1=$ systematic review, $2=$ randomized controlled trial, $3=$ cohort study, $4=$ case-controlled study,

$5=$ case report, $6=$ pharmacokinetic study, $7=$ animal study, $A=$ involves the listed drug pair, $B=$ involves drugs in the same class(es) as the listed drug pair.

A final major limitation of the study was the low response rate. An estimated $15 \%$ of survey recipients participated; therefore, the responses may reflect only a portion of the pharmacists who practise in our region.

\section{CONCLUSION}

A CDSS that is applicable in practice has the potential to be an invaluable tool for improving patient safety and reducing the workload of clinicians. However, there remain challenges in identifying and addressing gaps between the CDSS currently in use at the study institution and one that is operating at its full potential. The purpose of this study was to determine if various DDIs and their respective severity classifications in the CDSS aligned with the assessment of practising pharmacists. We identified a gap between the local CDSS and current clinical practice. Furthermore, the current CDSS did not have a large impact on clinical decision-making. The consequences of unidentified or improperly managed DDIs emphasize the need for an effective and applicable CDSS. Further research focused on determining and implementing approaches to improving the CDSS to enhance patient outcomes is warranted.

\section{References}

1. Tragni E, Casula M, Pieri V, Favato G, Marcobelli A, Trotta MG, et al. Prevalence of the prescription of potentially interacting drugs. PLoS One. 2013;8(10):e78827.

2. Miller L, Steinmetz Pater K, Corman S. The role of clinical decision support in pharmacist response to drug-interaction alerts. Res Soc Adm Pharm. 2015;11(3):480-6.

3. Reynolds JL, Rupp MT. Improving clinical decision support in pharmacy: toward the perfect DUR alert. J Manag Care Spec Pharm. 2017; 23(1):38-43.

4. Malone DC, Abarca J, Skrepnek GH, Murphy JE, Armstrong EP, Grizzle AJ, et al. Pharmacist workload and pharmacy characteristics associated with the dispensing of potentially clinically important drug-drug interactions. Med Care. 2007;45(5):456-62.

5. Ancker JS, Edwards A, Nosal S, Hauser D, Mauer E, Kaushal R; HITEC Investigators. Effects of workload, work complexity, and repeated alerts on alert fatigue in a clinical decision support system. BMC Med Inform Decis Mak. 2017;17:Article 36.

6. Bagri H, Dahri K, Legal M. Hospital pharmacists' perceptions and decision-making related to drug-drug interactions. Can J Hosp Pharm. 2019;72(4):288-94.

7. Tilson H, Hines LE, McEvoy G, Weinstein DM, Hansten PD, Matuszewski K, et al. Recommendations for selecting drug-drug interactions for clinical decision support. Am J Health Syst Pharm. 2016;73(8):576-85.

8. Saverno KR, Hiines LE, Warholak TL, Grizzle AJ, Babitis L, Clark C, et al. Ability of pharmacy clinical decision-support software to alert users about clinically important drug-drug interactions. J Am Med Inform Assoc. 2011;18(1):32-7. 
9. Amkreutz J, Koch A, Buendgens L, Trautwein C, Eisert A. Clinical decision support systems differ in their ability to identify clinically relevant drug interactions of immunosuppressants in kidney transplant patients. J Clin Pharm Ther. 2017;42(3):276-85.

10. Cornu P, Steurbaut S, Soštarić S, Mrhar A, Dupont AG. Performance of a clinical decision support system and of clinical pharmacists in preventing drug-drug interactions on a geriatric ward. Int J Clin Pharm. 2014;36(3):519-25.

11. Russ AL, Zillich AJ, McManus MS, Doebbeling BN, Saleem JJ. Prescribers' interaction with medication alerts at the point of prescribing: a multi-method, in situ investigation of the human-computer interaction. Int J Med Inform. 2012;81(4):232-43.

12. Yu KH, Sweidan M, Williamson M, Fraser A. Drug interaction alerts in software-what do general practitioners and pharmacists want? Med J Aust. 2011;195(11-12):678-80.

13. Smithburger PL, Buckley MS, Bejian S, Burenheide K, Kane-Gill SL. A critical evaluation of clinical decision support for the detection of drug-drug interaction. Expert Opin Drug Saf. 2011;10(6):871-82.

14. Zheng WY, Richardson LC, Li L, Day RO, Westbrook JI, Baysari MT. Drug-drug interactions and their harmful effects in hospitalised patients: a systematic review and meta-analysis. Eur J Clin Pharmacol. 2018:74(1):15-7.

15. Rosas-Carrasco O, García-Peña C, Sánchez-García S, Vargas-Alarcón G, Gutiérrez-Robledo LM, Juárez-Cedillo T. The relationship between potential drug-drug interactions and mortality rate of elderly hospitalized patients. Rev Invest Clin. 2011:63(6):564-73.
Louise Lau, BSC, BSc Pharm, ACPR, is a Clinical Pharmacist with Vancouver General Hospital, Vancouver, British Columbia.

Harkaryn Bagri, BSC, BScPharm, ACPR, is a Clinical Pharmacist with Surrey Memorial Hospital, Surrey, British Columbia.

Michael Legal, BScPharm, PharmD, ACPR, FCSHP, is a Clinical Manager with Lower Mainland Pharmacy Services, Vancouver, British Columbia.

Karen Dahri, BSc, BScPharm, PharmD, ACPR, FCSHP, is a Clinical

Pharmacotherapeutic Specialist (Internal Medicine) with Vancouver General Hospital and an Assistant Professor (Partner) with the Faculty of Pharmaceutical Sciences, The University of British Columbia, Vancouver, British Columbia.

Competing interests: None declared.

\section{Address correspondence to:}

\section{Dr Karen Dahri}

Pharmaceutical Sciences

Vancouver General Hospital

855 West 12th Avenue

Vancouver BC V5Z $1 \mathrm{M} 9$

email: Karen.Dahri@vch.ca

Funding: This study was funded through an unrestricted start-up research grant to Karen Dahri.

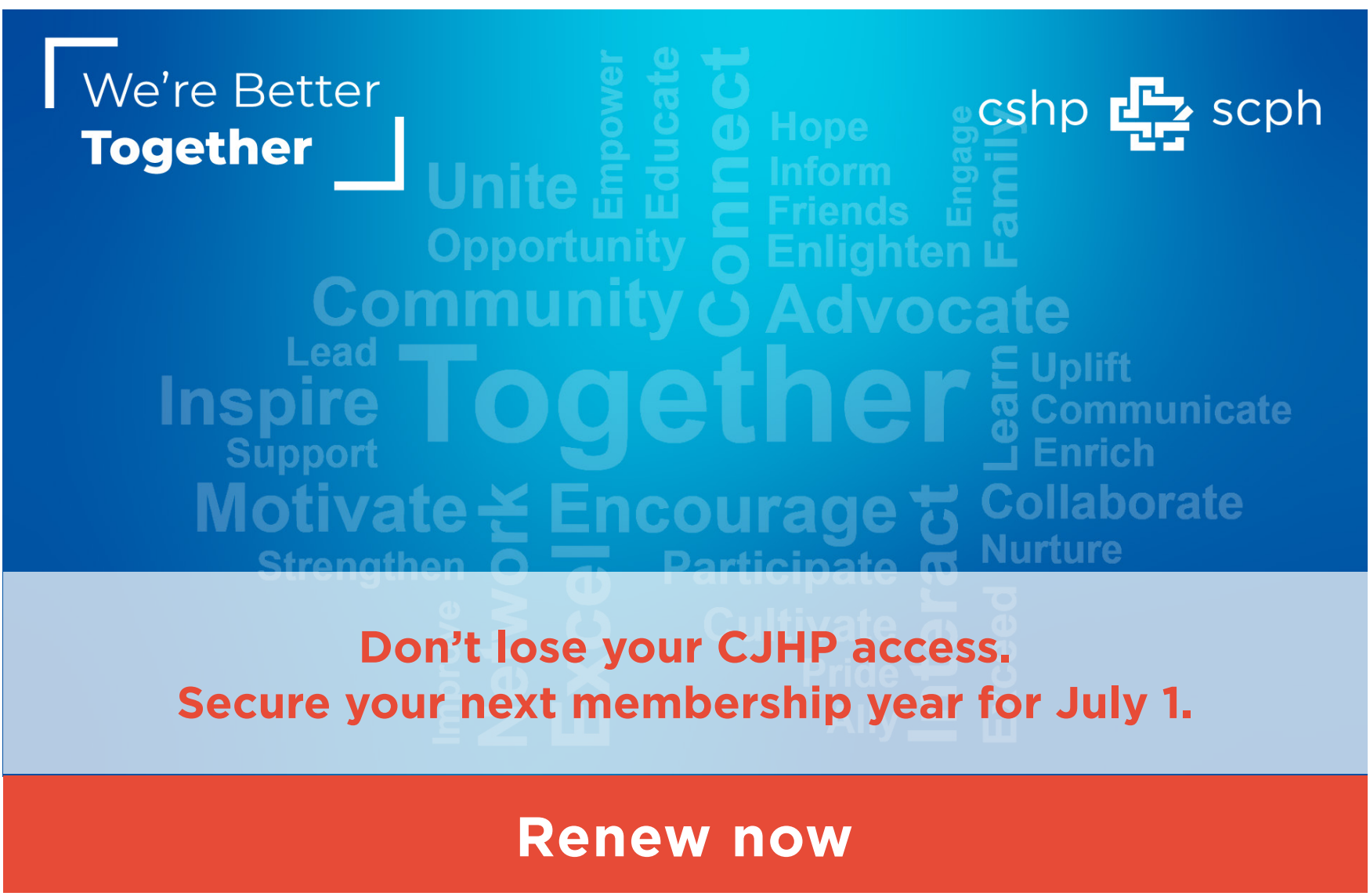

